\title{
Paravalvular regurgitation after conventional aortic and mitral valve replacement: A benchmark for alternative approaches
}

\author{
Brett F. Duncan, MD, ${ }^{a}$ Patrick M. McCarthy, MD, ${ }^{\mathrm{a}}$ Jane Kruse, RN, BSN, ${ }^{\mathrm{a}}$ Adin-Cristian Andrei, PhD, ${ }^{\mathrm{a}}$ \\ Zhi Li, MS, ${ }^{a}$ Hyde M. Russell, MD, ${ }^{a}$ Travis O. Abicht, MD, ${ }^{a}$ Vera H. Rigolin, MD, ${ }^{b}$ James D. Thomas, MD, \\ Charles J. Davidson, MD, ${ }^{\mathrm{b}}$ Robert O. Bonow, MD, ${ }^{\mathrm{b}}$ and S. Chris Malaisrie, MD
}

\begin{abstract}
Objective: Paravalvular regurgitation is a known complication after transcatheter and sutureless aortic valve replacement. Paravalvular regurgitation also may develop in patients undergoing percutaneous mitral valve replacement. There are few studies on contemporary surgical valve replacement for comparison. We sought to determine the contemporary occurrence of paravalvular regurgitation after conventional surgical valve replacement.
\end{abstract}

Methods: We performed a single-center retrospective database review involving 1774 patients who underwent valve replacement surgery from April 2004 to December 2012: aortic in 1244, mitral in 386, and combined aortic and mitral in 144. Follow-up echocardiography was performed in $73 \%$ of patients. Patients with endocarditis were analyzed separately from noninfectious paravalvular leaks. Statistical comparisons were performed to determine differences in paravalvular regurgitation incidence and survival.

Results: During follow-up, $1+$ or greater (mild or more) paravalvular regurgitation occurred in $2.2 \%$ of aortic cases and $2.9 \%$ of mitral cases. There was $2+$ or greater (moderate or more) paravalvular regurgitation in $0.9 \%$ of aortic and $2.2 \%$ of mitral cases $(P=.10)$. After excluding endocarditis, late noninfectious regurgitation $2+$ or greater was detected in $0.5 \%$ of aortic and $0.4 \%$ of mitral cases $(P=.93)$; there were no reoperations or percutaneous closures for noninfectious paravalvular regurgitation.

Conclusions: In an academic medical center, the overall rate of paravalvular regurgitation is low, and late clinically significant noninfectious paravalvular regurgitation is rare. The benchmark for paravalvular regurgitation after conventional valve replacement is high and should be considered when evaluating patients for transcatheter or sutureless valve replacement. (J Thorac Cardiovasc Surg 2015;150:860-8)

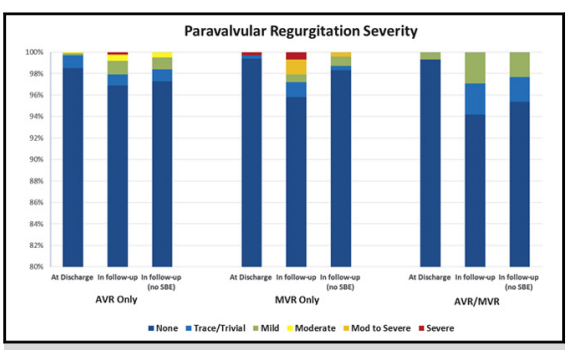

PVR in valve replacement surgery. Incidence of PVR at discharge and in follow-up including and excluding subacute bacterial endocarditis.

\section{Central Message}

The incidence of PVR today after conventional valve replacement is rare and should be compared with transcatheter and sutureless valves.

\section{Perspective}

PVR is a known complication of transcatheter and sutureless valve replacement and should be compared with the low incidence of PVR in conventional surgical replacement when counseling patients. As the use of TAVR expands to lower-risk groups, sutureless aortic valves gain commercial approval, and trials on transcatheter MVR begin, this low incidence after conventional replacement should be considered.

See Editorial Commentary page 868 .
Supplemental material is available online.

Paravalvular regurgitation (PVR) is a known complication of transcatheter aortic valve replacement (TAVR) and occurs at a higher rate after TAVR than after conventional

From the Divisions of a Cardiac Surgery and ${ }^{\mathrm{b}}$ Cardiology, Bluhm Cardiovascular Institute, Northwestern University Feinberg School of Medicine, Chicago, Ill. Received for publication March 25, 2015; revisions received June 15, 2015; accepted for publication June 19, 2015; available ahead of print July 26, 2015.

Address for reprints: Patrick M. McCarthy, MD, Division of Cardiac Surgery, Bluhm Cardiovascular Institute, Northwestern University Feinberg School of Medicine, surgical aortic valve replacement (AVR). ${ }^{1}$ In the Placement of Aortic Transcatheter Valves (PARTNER) trial for both inoperable and high-risk surgical patients, the incidence of mild or greater PVR $(\geq 1+)$ after TAVR was reported to be approximately $40 \%$, with $7 \%$ to $12 \%$ moderate to severe PVR $(\geq 2+)$ depending on the cohort. ${ }^{2-4}$ At both 1 and 2 years, PVR $2+$ or greater was more common after TAVR than after surgical AVR $(7.0 \%$ vs $1.9 \%$ at 1 year and $6.9 \%$

201 East Huron St, Suite 11-140, Chicago, IL 60611-2908 (E-mail: pmccart@ nm.org).

$0022-5223 / \$ 36.00$

Copyright (C) 2015 by The American Association for Thoracic Surgery

http://dx.doi.org/10.1016/j.jtcvs.2015.06.047 


\section{Abbreviations and Acronyms \\ AVR $=$ aortic valve replacement \\ MVR $=$ mitral valve replacement \\ PVR = paravalvular regurgitation \\ TAVR $=$ transcatheter aortic valve replacement \\ TEE $=$ transesophageal echocardiography}

vs $0.9 \%$ at 2 years). Furthermore, the presence of mild or greater PVR after TAVR was associated with increased late mortality. ${ }^{4}$ The US CoreValve trial reported a higher incidence of PVR $2+$ or greater at 1 year for TAVR versus surgical AVR $(6.1 \%$ vs $0.5 \%)$, but PVR did not have an adverse effect on overall survival at 1-year follow-up.

Conventional surgical AVR has a reported incidence of PVR between $2 \%$ and $17 \%{ }^{6,7}$ A recent study found an incidence of PVR $2+$ or greater in $4.2 \%$ of patients with surgical AVR. ${ }^{8}$ Rarely did these studies separate infectious causes of PVR from noninfectious PVR, possibly a more appropriate comparison with PVR in TAVR. Recent literature on TAVR reports historical PVR rates in surgical AVR between $1 \%$ and $47 \%$, perhaps significantly higher than the contemporary surgical PVR frequency. ${ }^{9}$ Sutureless aortic valve devices are currently approved in Europe and undergoing clinical trials in the United States. These devices also have a notable incidence of PVR. ${ }^{10,11}$ Furthermore, clinical trials are beginning for percutaneous mitral valve replacement (MVR), and PVR will be evaluated in these devices.

The contemporary incidence of PVR in conventional AVR and MVR may be significantly lower than reported in the historical literature. With TAVR, sutureless surgical AVR, and transcatheter MVR facing a technical challenge of PVR, we reviewed our incidence of PVR after conventional AVR and MVR for comparison with these new technologies. Further, we separated the incidence of noninfectious PVR from infectious PVR to provide a more relevant comparison with TAVR.

\section{MATERIALS AND METHODS \\ Patient Selection}

A single-center retrospective cohort study was performed using the Cardiovascular Research Database of the Clinical Trials Unit at the Bluhm Cardiovascular Institute of Northwestern University. The database was approved by the Institutional Review Board at Northwestern University (\#STU00012288). Any subject refusing participation in the database was not included in the analysis, and there were 96 patients $(96 / 1870,5 \%)$ excluded from this cohort because of refusal to participate. The Cardiovascular Research Database was queried for patients who underwent AVR, MVR, or double-valve (AVR + MVR) surgery with or without other concomitant cardiac procedures, such as coronary artery bypass grafting, at Northwestern Memorial Hospital from April 2004 to December 2012. Patients who received aortic valve-sparing root replacement, composite AVR, aortic homografts, and TAVR were excluded. The study cohort was divided into 3 groups consisting of patients undergoing AVR only, MVR only, and AVR + MVR.
Patients underwent routine intraoperative transesophageal echocardiography (TEE) and transthoracic echocardiography before hospital discharge. Extra care is taken to evaluate the prosthetic valve in postoperative patients in our laboratory. The information from the intraoperative TEE is available to the sonographer performing the predischarge transthoracic echocardiography and the cardiologist reading the study. This allows for correlation with additional intraoperative information if PVR is suspected and thus maximizes the accuracy of the study. Follow-up echocardiography was performed at the discretion of the patient's primary cardiologist. PVR was defined as blood flow between the valve sewing ring and the native valve annulus. ${ }^{12}$ PVR severity includes only the portion of total regurgitation resultant from the paravalvular component. The severity of PVR was graded using the composite echocardiographic criteria recommended by the American Society of Echocardiography and was standard in our institution throughout the time period. ${ }^{13,14}$ PVR was identified by database review of echocardiography reports. Echocardiographic findings were analyzed in 3 categories: intraoperative, hospital discharge, and followup. Severity of PVR was recorded and classified to be inclusive of all PVR. These were categorized as none, trace or trivial, mild $(1+)$, moderate $(2+)$, moderate to severe $(3+)$, and severe $(4+)$ regurgitation. We defined 3 different PVR classes: (1) any PVR in follow-up, which includes all PVR detected on echocardiography, graded trivial to severe; (2) PVR 1+ or greater, defined to include all regurgitation mild to severe, thus providing comparison basis with historical literature in surgical valve replacement; and (3) clinically significant PVR, meaning PVR 2+ or greater (moderate to severe), which most closely resembles the commonly reported PVR rates in TAVR studies. ${ }^{15-17}$ All available echocardiogram reports for an individual patient were reviewed for the presence of PVR. For the analysis, the most recent echocardiogram report was used to determine the incidence and severity of PVR as in our review; the presence and severity of PVR rarely changed during follow-up.

The primary end point was the incidence and severity of PVR intraoperatively, at discharge, and in follow-up. A further analysis was performed of noninfectious PVR incidence in follow-up. Patients after the index Northwestern index procedure were diagnosed with infective endocarditis after valve replacement on the basis of preoperative positive blood cultures, clinical condition of the patient, echocardiogram reports, and intraoperative findings. This was performed to clarify PVR incidence due to (1) early technical issues leading to a second crossclamp; (2) other anatomic factors (eg, calcification or tissue fragility) leading to late PVR, more relevant to PVR after TAVR; and (3) PVR caused by late endocarditis.

\section{Surgical Technique}

Valves were implanted using conventional, multiple interrupted suture technique through standard median sternotomy, mini-sternotomy, or thoracotomy. Almost all valves were placed with the annulus ringed by interrupted horizontal mattress sutures using pledgeted, braided polyester suture. The sutures were passed through the sewing ring, and the valves were seated and secured with hand-tied knots. Continuous, running suture and mechanical clips were not used. Pledgets were placed below the aortic annulus (supra-annular valves) or on the left atrial side for mitral valves.

\section{Statistical Analysis}

Data continuously distributed were summarized using means \pm standard deviations or median with interquartile range $(\mathrm{Q} 1, \mathrm{Q} 3)$. Categoric data were shown as counts and percentages. Baseline characteristics, operative data, and outcomes were compared between groups using the equal-variance 2sample $t$ test, analysis of variance, or Wilcoxon rank-sum test for continuous variables. The chi-square or Fisher exact test was used in group comparisons involving categoric variables. Overall survival curves were constructed using the Kaplan-Meier estimator, and groups were compared on the basis of the log-rank test. Patients were included in the follow-up analysis if they were alive at 30 days after their operation. Statistical significance was declared at the 2 -sided $5 \%$ alpha level, and there were no adjustments for 
TABLE 1. Baseline and perioperative characteristics

\begin{tabular}{|c|c|c|c|c|}
\hline Variable & $\operatorname{AVR}(\mathbf{N}=1244)$ & $\operatorname{MVR}(\mathbf{N}=\mathbf{3 8 6})$ & $\operatorname{AVR}+\operatorname{MVR}(N=144)$ & $P$ value \\
\hline Age, y & $70.0 \pm 13.1$ & $63.9 \pm 13.9$ & $67.8 \pm 13.1$ & $<.001$ \\
\hline Female gender & $445(36 \%)$ & $235(61 \%)$ & $95(66 \%)$ & $<.001$ \\
\hline Body mass index & $28.5 \pm 6.2$ & $27.9 \pm 6.2$ & $27.0 \pm 5.9$ & .008 \\
\hline NYHA functional class $\geq$ III & $495(40 \%)$ & $199(52 \%)$ & $70(49 \%)$ & $<.001$ \\
\hline Ejection fraction & $60.0(50.0-65.0)$ & $60.0(50.0-63.0)$ & $60.0(55.0-65.0)$ & .24 \\
\hline Prior stroke & $84(7 \%)$ & $47(12 \%)$ & $17(12 \%)$ & .001 \\
\hline Repeat sternotomy & $234(19 \%)$ & $152(39 \%)$ & $53(37 \%)$ & $<.001$ \\
\hline Perfusion time (min) & $96.0(73.0-128.0)$ & $122.0(96.0-154.0)$ & $169.5(131.0-197.5)$ & $<.001$ \\
\hline Crossclamp time (min) & $77.0(60.0-102.0)$ & $87.5(71.0-112.0)$ & $132.0(112.0-161.0)$ & $<.001$ \\
\hline CABG & $451(36 \%)$ & $88(23 \%)$ & $51(35 \%)$ & $<.001$ \\
\hline Aortic valve surgery & $1244(100 \%)$ & $36(9 \%)$ & $144(100 \%)$ & $<.001$ \\
\hline Aortic stenosis & $1043(86 \%)$ & $22(7 \%)$ & $100(74 \%)$ & $<.001$ \\
\hline Aortic regurgitation $\geq 2+$ & $422(34 \%)$ & $39(12 \%)$ & $72(52 \%)$ & $<.001$ \\
\hline Mitral valve surgery & $115(9 \%)$ & $386(100 \%)$ & $144(100 \%)$ & $<.001$ \\
\hline Mitral stenosis & $58(5 \%)$ & $121(35 \%)$ & $75(57 \%)$ & $<.001$ \\
\hline Mitral regurgitation $\geq 2+$ & $243(20 \%)$ & $304(81 \%)$ & $97(68 \%)$ & $<.001$ \\
\hline Tricuspid valve surgery & $73(6 \%)$ & $138(36 \%)$ & $41(28 \%)$ & $<.001$ \\
\hline 30-d mortality & $30(2 \%)$ & $21(5 \%)$ & $6(4 \%)$ & .010 \\
\hline All-cause long-term mortality & $201(16 \%)$ & $80(21 \%)$ & $36(25 \%)$ & .008 \\
\hline
\end{tabular}

$A V R$, Aortic valve replacement; $C A B G$, coronary artery bypass grafting; $M V R$, mitral valve replacement; $N Y H A$, New York Heart Association.

multiplicity. Statistical analysis was completed using SAS statistical software (version 9.3; SAS Institute Inc, Cary, NC).

\section{RESULTS}

A total of 1774 patients underwent valve replacement with or without other cardiac procedures. Of these, 1244 patients (aged $70.0 \pm 13.1$ years) underwent AVR, 386 patients (aged $63.9 \pm 13.9$ years) underwent MVR, and 144 patients (aged $67.8 \pm 13.1$ years) underwent double-valve replacement. Concomitant coronary artery bypass grafting was performed in $33 \%$ of patients $(590 / 1774)$, a cardiac reoperation was performed in $25 \%$ of patients (439/1774), and an elective procedure was performed in $84 \%$ of patients (1488/1774). In the aortic position, $98 \%$ of patients (1358/ 1388) received tissue valve replacement and $2 \%$ of patients (30/1388) received mechanical replacement. In the mitral position, $94 \%$ of patients $(496 / 530)$ received tissue valve replacement and $6 \%$ of patients (34/530) received mechanical replacement. The 30-day mortality was $2.4 \%$ (30/ $1244), 5.4 \%(21 / 386)$, and $4.2 \%(6 / 144)$ for patients undergoing AVR, MVR, and AVR + MVR, respectively. TEE was performed intraoperatively in $100 \%$ of patients, with transthoracic studies at discharge in $100 \%$ and during follow-up in $73 \%$ of total patients (1255/1713), including $72 \%$ of patients $(873 / 1214)$ undergoing AVR only (mean follow-up, $2.4 \pm 2.2$ years; range, $0-9.4$ years), $77 \%$ of patients (279/362) undergoing MVR only (mean follow-up, $2.3 \pm 2.1$ years; range, $0-8.9$ years), and $75 \%$ of patients (103/137) undergoing AVR + MVR (mean follow-up, $2.3 \pm 2.1$ years; range, 0-8.6 years). Clinical follow-up was available in $90 \%$ of patients $(1089 / 1214)$ undergoing AVR only, $90 \%$ of patients (327/362) undergoing MVR only, and $88 \%$ of patients (120/137) undergoing AVR + MVR. Intraoperative and perioperative data are shown in Table 1. The groups differed significantly in the majority of measured variables given the different patient populations and technical aspects of each operation.

Among the 1244 patients undergoing AVR, intraoperative TEE identified 10 patients $(0.8 \%, 10 / 1244)$ with PVR (Figure 1, $A$ and Table E1). Five patients $(0.4 \%, 5 / 1244)$ had trivial to mild regurgitation and did not require a second crossclamp for PVR repair. Four patients with mild or greater $(\geq 1+)$ PVR were put back on bypass and underwent a second crossclamp with successful repair of the PVR. One patient undergoing AVR for complex prosthetic valve endocarditis had moderate $(2+)$ regurgitation that required a second crossclamp and had persistent mild $(1+)$ regurgitation after repair. In total, 5 patients $(0.4 \%, 5 / 1244)$ underwent a second crossclamp for PVR repair. At discharge, 3 of 1214 patients $(0.2 \%, 3 / 1214)$ had PVR $1+$, and there was no intervention (Figure 2 and Table E2). One patient $(0.1 \%, 1 / 1214)$ with PVR $2+$ did not undergo a reoperation and in follow-up had PVR 1+. No patient had PVR 3+ or $4+$ at discharge. Among the 873 patients who underwent AVR with follow-up echocardiography, 19 (2.2\%, 19/ 873) had PVR $1+$ or greater at any time point, including $11(1.3 \%, 11 / 873)$ with PVR $1+$ and $8(0.9 \%, 8 / 873)$ with clinically significant PVR $2+$ or greater. The rate of PVR $2+$ or greater was $0.4 \%$ per person-year. Six of the 19 patients with PVR had infectious endocarditis, 4 of whom had PVR 2+ or greater. After excluding patients who had PVR related to endocarditis, 9 patients $(1.1 \%, 9 /$ 832) had $1+$ noninfectious PVR, 4 patients $(0.5 \%, 4 / 832)$ had PVR $2+$, and none had noninfectious PVR $3+$ or $4+$. 

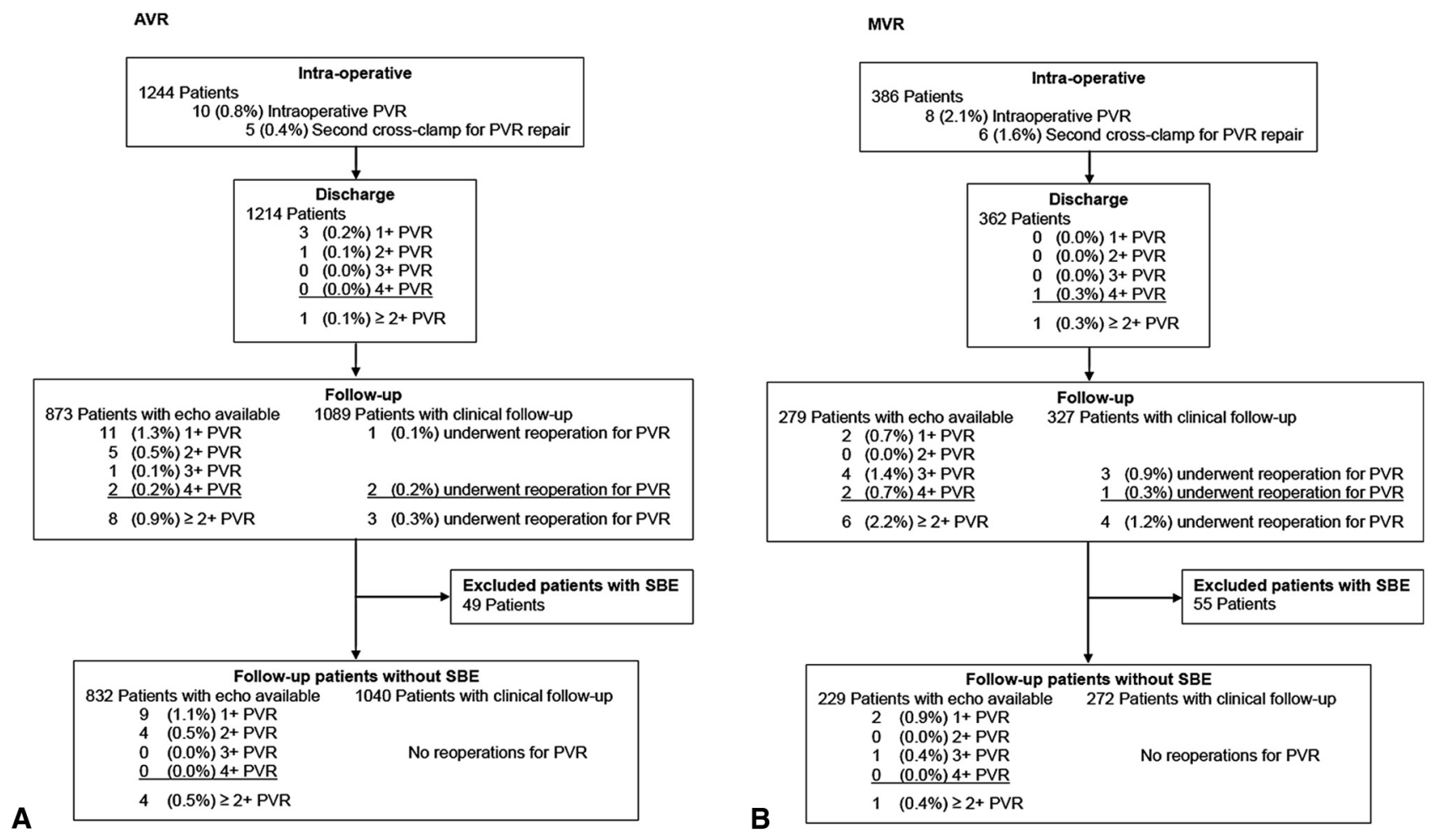

AVRIMVR

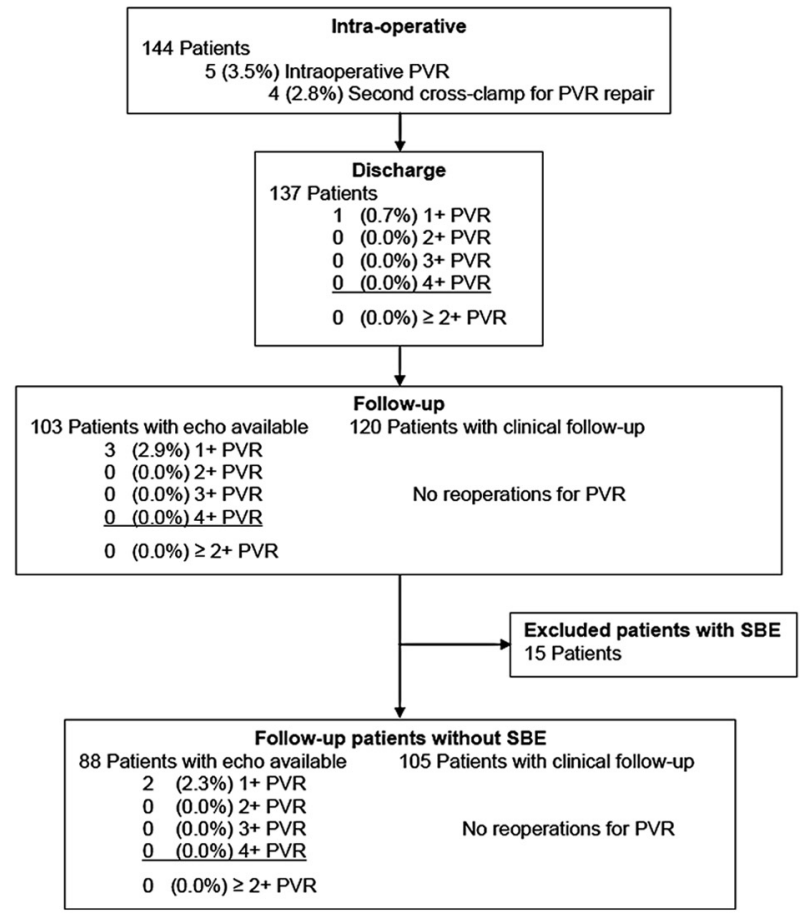

FIGURE 1. PVR incidence and reinterventions. PVR incidence by severity at discharge and in follow-up including and excluding endocarditis for AVR (A), MVR (B), and AVR + MVR (C) cohorts. Reinterventions include second crossclamp for repair during index operation or reoperation in follow-up. Incidence of PVR $1+$ or $2+$ or greater was not significantly different between groups at any time point. Significant differences in intraoperative PVR $(P=.009)$, second crossclamp for repair $(P=.003)$, and reoperation for PVR in follow-up (AVR vs MVR, $P=.032)$. AVR, Aortic valve replacement; $M V R$, mitral valve replacement; $P V R$, paravalvular regurgitation; $S B E$, subacute bacterial endocarditis. 


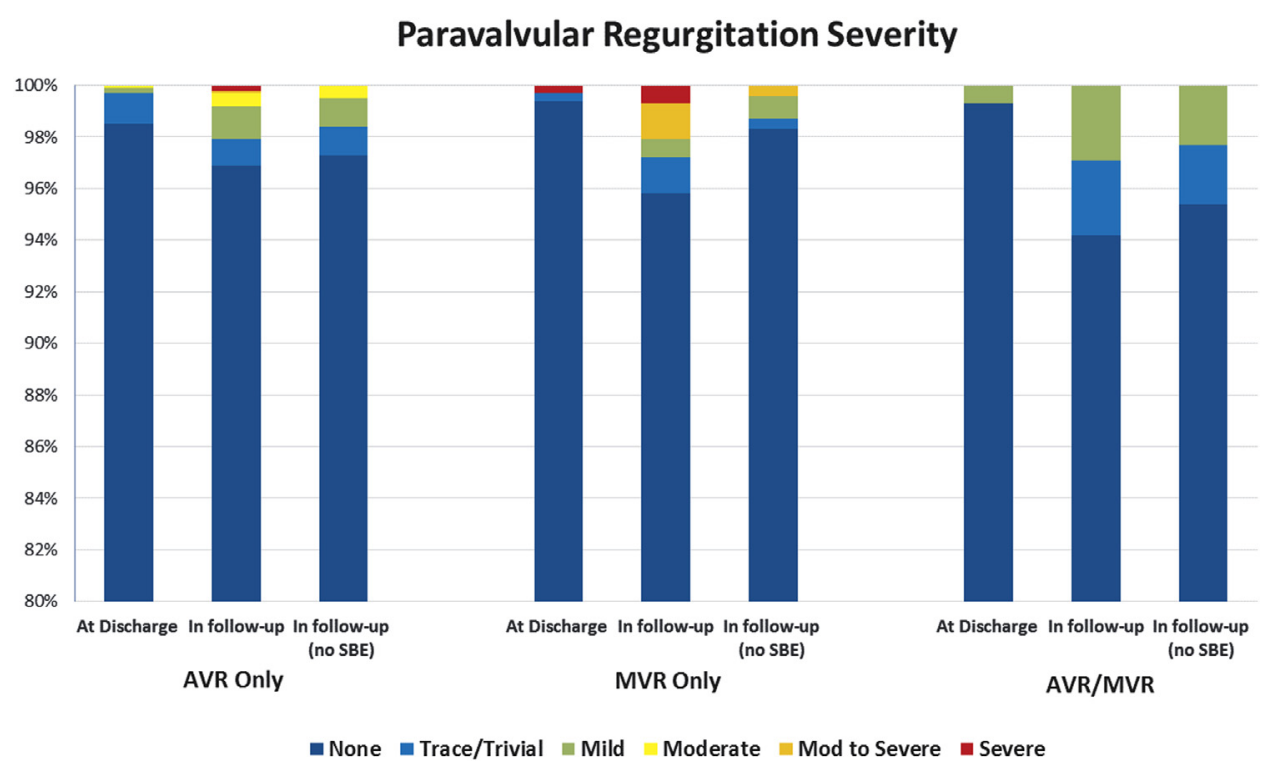

FIGURE 2. PVR in valve replacement surgery. Incidence of PVR at discharge and in follow-up including and excluding subacute bacterial endocarditis. Overall incidence of mild to severe PVR $(\geq 1+)$ during follow-up was $2.2 \%, 2.9 \%$, and $2.9 \%$ for AVR, MVR, and AVR + MVR cases, respectively. Clinically significant moderate or greater PVR $(\geq 2+)$ occurred in $0.9 \%$ of patients after AVR, $2.2 \%$ of patients after MVR, and $0 \%$ of patients after AVR + MVR, and in only $0.5 \%$ of AVR and $0.4 \%$ of MVR cases after excluding subacute bacterial endocarditis. AVR, Aortic valve replacement; $M V R$, mitral valve replacement; $S B E$, subacute bacterial endocarditis.

There were 3 reoperations $(0.3 \%, 3 / 1089)$ for PVR related to endocarditis during follow-up. There were no reoperations for noninfectious PVR.

Among patients undergoing MVR, 8 of 386 (2.1\%) had PVR identified on intraoperative TEE (Figure 1, B). Six patients $(1.6 \%, 6 / 386)$ had a second crossclamp for PVR repair that was successful in 5 patients, and 1 patient $(1 / 386$ [0.3\%]) had persistent PVR 1+ after repair but no PVR on predischarge echocardiography. At discharge, 1 of 362 patients $(0.3 \%)$ had severe (4+) PVR but did not undergo reintervention because of postoperative intracranial hemorrhage. There were no patients with PVR $1+, 2+$, or $3+$ at discharge. There were 279 patients undergoing MVR only with a follow-up echocardiogram. PVR at any time point occurred in 8 patients $(2.9 \%, 8 / 279)$, including $2(0.7 \%$, $2 / 279)$ with PVR $1+$ and $6(2.2 \%, 6 / 279)$ with PVR $2+$ or greater. The rate of PVR $2+$ or greater was $1.1 \%$ per person-year. PVR related to endocarditis accounted for 5 of the 8 instances, including 5 of the 6 with PVR $2+$ or greater. After excluding PVR from endocarditis, 2 patients $(0.9 \%, 2 / 229)$ had noninfectious PVR $1+$ and 1 patient $(0.4 \%, 1 / 229)$ had noninfectious PVR $2+$ or greater. There were 4 reoperations $(1.2 \%, 4 / 327)$ for PVR, all related to endocarditis with no reoperations for noninfectious PVR.

Combined AVR and MVR was performed in 144 patients. Five patients $(3.5 \%, 5 / 144)$ had regurgitation on intraoperative TEE, of whom $4(2.8 \%, 4 / 144)$ with $1+$ or greater PVR underwent a second crossclamp for PVR repair (Figure 1, C). All intraoperative PVR cases involved the mitral valve and were successfully repaired. One patient
$(0.7 \%, 1 / 137)$ had $1+$ aortic PVR at discharge but did not have a follow-up echocardiogram. There were no patients with PVR 2+ or greater at discharge. In 103 patients with follow-up echocardiograms, $3(2.9 \%, 3 / 103)$ had PVR $1+$ at any time, 1 aortic and 2 mitral, and none had PVR 2+ or greater. One patient with $1+$ mitral PVR had endocarditis, 1 patient had $1+$ noninfectious aortic PVR, and 1 patient had 1+ noninfectious mitral PVR. No patients undergoing double-valve replacement had PVR in both valves. In the patients undergoing AVR + MVR, there were no reoperations for PVR. Across all AVR and MVR cases, there were no reoperations for noninfectious PVR or catheterbased reinterventions for PVR.

To determine the differences in PVR incidence and severity between valves placed in the aortic or mitral positions, the AVR only and MVR only groups were compared. In unadjusted analyses, the MVR group underwent significantly more second crossclamps for repair of PVR $(P=.016)$ and required more reoperations for PVR in follow-up $(P=.032)$. There were no significant differences in incidence or severity of PVR at discharge or in follow-up.

Figure 3 presents Kaplan-Meier survival curves for the patients undergoing AVR and MVR. Survival based on presence of PVR at discharge was stratified as no PVR versus any PVR from trivial to severe. For the survival analysis based on PVR in follow-up, the 2 groups were stratified as no or trace PVR versus PVR $1+$ or greater. There was no significant association between PVR and survival in AVR cases. PVR at discharge and in follow-up for MVR cases was significantly associated with decreased survival $(P=.0024$ and $P=.01$, respectively). 


\section{Stratified by Disch arge PVR (Trivial to Severe)}
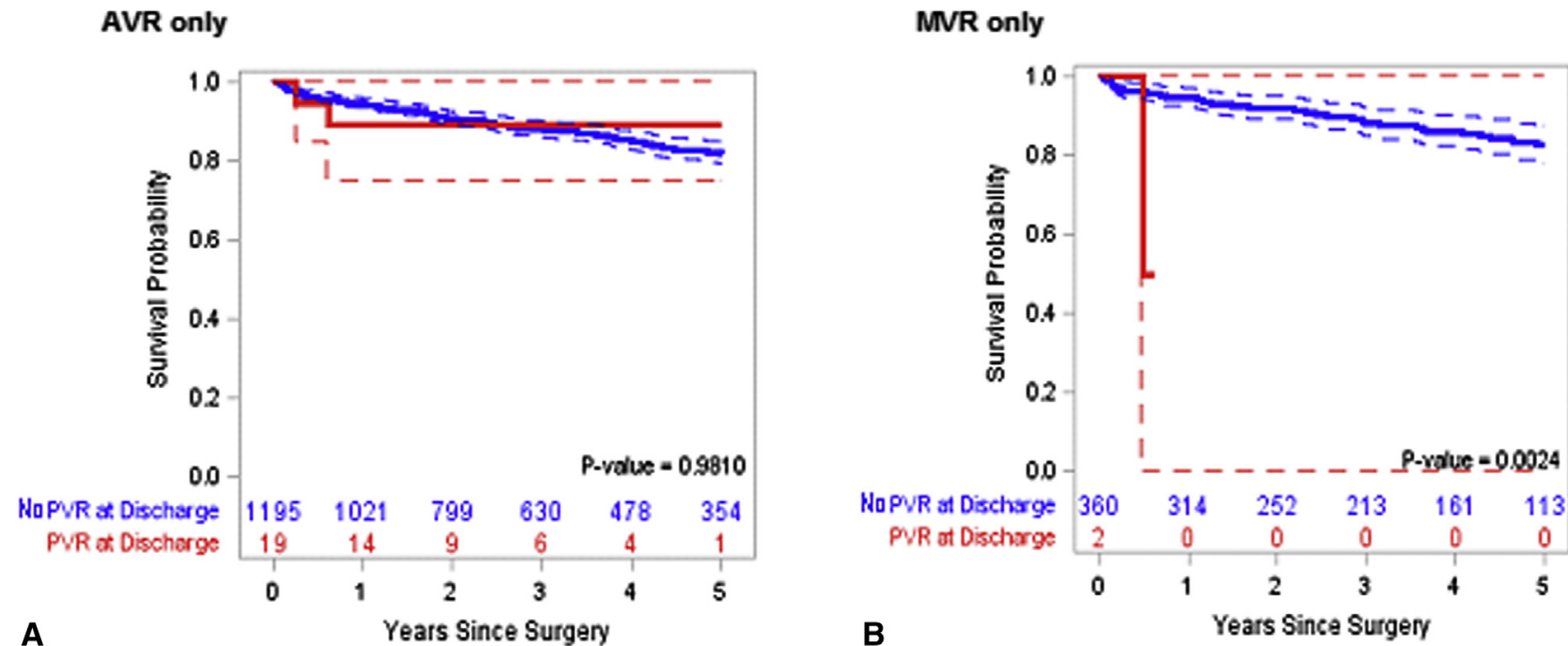

A

Stratified by Follow-up PVR (Mild to Severe)

AVR only

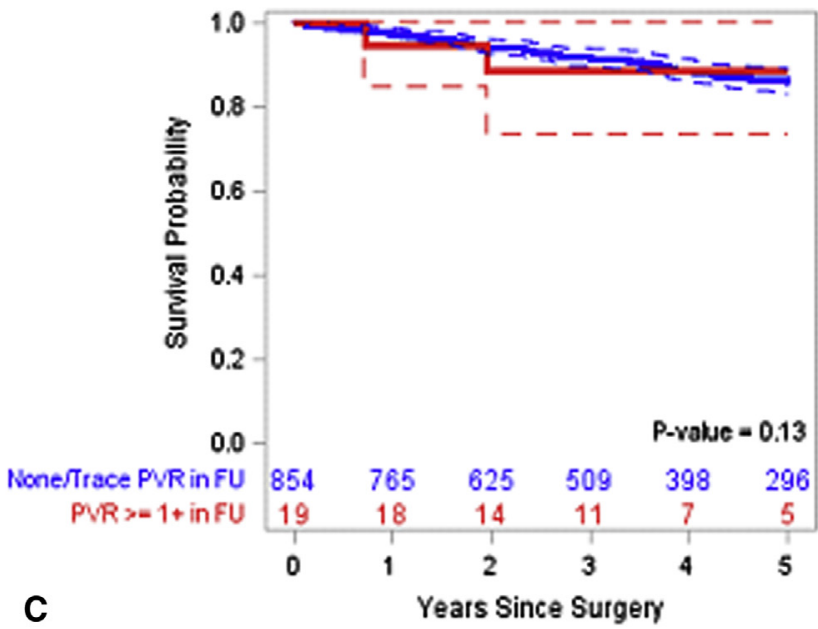

MNR only

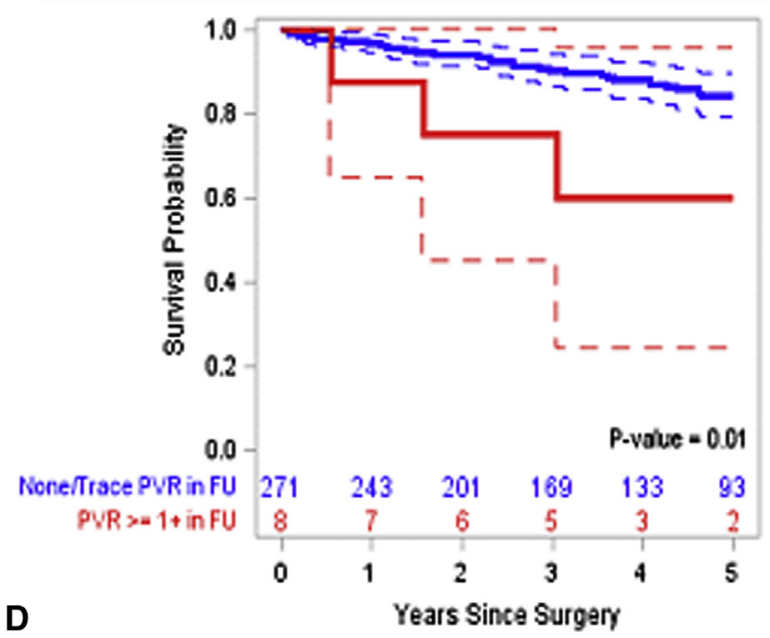

FIGURE 3. Kaplan-Meier survival estimates. Kaplan-Meier estimates of medium-term overall survival stratified by presence of trivial of greater PVR at discharge in patients undergoing AVR (A) and MVR (B) and by mild or greater PVR in follow-up in patients undergoing AVR (C) and MVR (D). AVR, Aortic valve replacement; $F U$, follow-up; $M V R$, mitral valve replacement; $P V R$, paravalvular regurgitation.

\section{DISCUSSION}

In our study, the overall incidence of mild to severe PVR $(\geq 1+$ ) during follow-up was $2.2 \%$ for patients undergoing AVR, $2.9 \%$ in patients undergoing MVR, and $2.9 \%$ in patients undergoing combined AVR + MVR. The incidence of clinically significant moderate or greater PVR $(\geq 2+)$ was $0.9 \%$ after AVR, $2.2 \%$ after MVR, and $0 \%$ after AVR + MVR. After excluding patients with endocarditis, noninfectious PVR $2+$ or greater occurred in only $0.5 \%$ of AVR and $0.4 \%$ of MVR cases. In unadjusted analyses, patients undergoing MVR were significantly more likely than patients undergoing AVR to require early reintervention for PVR during the initial operation and reoperation for PVR during subsequent follow-up. The incidence or severity of PVR did not differ significantly between AVR and MVR cases.

\section{Previous Studies of Surgical Paravalvular Regurgitation}

There is renewed interest in PVR because its prevalence is significantly higher after TAVR than after surgical AVR, and historical surgical literature is often cited for 
comparison. Recent TAVR and surgical PVR studies report that mild PVR after surgical AVR is not uncommon, with reported PVR rates between $1 \%$ and $47 \% .{ }^{9,18-20}$ In the most frequently cited studies, conventional surgical AVR has a reported PVR incidence between $2 \%$ and $17 \%{ }^{6,7,12,21}$ In comparison, the overall incidence of PVR $1+$ or greater after AVR in the current study was $2.2 \%$. Sponga and colleagues ${ }^{8}$ reported an incidence of moderate to severe PVR of $4.2 \%$ in 3201 patients undergoing surgical AVR from 1992 to 2011. In our study, clinically significant PVR $2+$ or greater occurred in $0.9 \%$ of patients.

After MVR, the reported incidence of PVR ranges between $7 \%$ and $22 \%{ }^{6,7,21,22}$ The current data indicate an overall incidence of PVR $1+$ or greater of $2.9 \%$ and PVR $2+$ or greater of $2.2 \%$ among patients undergoing MVR. Advances in surgical valve technology, refinement of surgical technique, and experience have most likely contributed to contemporary PVR rates at or below the lower end of the historical reported incidence, even with ever-improving echocardiographic technology. In a recent study, Taramasso and colleagues ${ }^{19}$ reported that the surgical treatment of PVR is still high and that long-term outcomes remain suboptimal. Future comparisons with TAVR data and emerging technologies such as sutureless AVR and percutaneous MVR should consider the significantly lower contemporary rate of PVR after surgical AVR and MVR.

\section{Comparison With Transcatheter Aortic Valve Replacement Studies}

In the PARTNER trial, moderate to severe PVR occurred in $7 \%$ to $12 \%$ of patients after TAVR. ${ }^{2,4}$ Two other recently published randomized controlled trials of TAVR contribute further to the evidence base. In the CoreValve trial, moderate to severe PVR was reported in $6.1 \%$ of patients at 1 year. ${ }^{5}$ The CHOICE trial reported more than mild aortic PVR in $4.1 \%$ versus $18.3 \%$ of the balloon-expandable and self-expandable TAVR groups, respectively. ${ }^{23}$ Several meta-analyses of TAVR studies report overall rates of moderate to severe PVR of $7.4 \%$, ranging from $3.9 \%$ to $15.8 \%$ depending on the valve type. ${ }^{24,25}$ To our knowledge, the current data are the first to separate a noninfectious PVR incidence that provides a more similar surgical AVR group for comparison with TAVR. The $1.6 \%$ incidence of noninfectious PVR $1+$ or greater and $0.5 \%$ incidence of noninfectious PVR $2+$ or greater after surgical AVR further reinforce the conclusion that TAVR results in PVR rates that are higher than those of contemporary surgical AVR. Second- and third-generation TAVR valves have been developed with 1 of their goals being to address PVR. Many are in early clinical trials in Europe and North America, and short-term follow-up is now appearing in the published literature. Several clinical studies have reported 30 -day results with PVR of moderate or greater in $1 \%$ to $3.5 \%$ of patients and $15 \%$ to $28 \%$ with mild PVR. ${ }^{26-28}$
Available results at 1 year reported moderate to severe PVR of $6.2 \%$ and mild PVR of $24.1 \% .^{29}$ These newergeneration TAVR valves have improved on the incidence of PVR after TAVR but still remain higher than the contemporary late PVR incidence in surgical AVR reported in this study of $1.3 \%$ mild and $0.9 \%$ moderate to severe with a noninfectious incidence of $0.5 \%$ moderate to severe PVR.

Many of the clinical trials for TAVR have included a surgical control group undergoing surgical AVR who had similar comorbidities and surgical risk estimates. The rates of PVR $2+$ or greater in the surgical controls are sometimes reported but rarely highlighted in these studies. In the PARTNER trial, PVR in patients randomized to surgical AVR occurred in $1.9 \%$ at 1 year and $0.9 \%$ at 2 years. ${ }^{4}$ Likewise, the CoreValve trial reported moderate to severe PVR in $0.5 \%$ of patients undergoing surgical AVR at 1 year. $^{5}$ These results are consistent with both the overall and the noninfectious clinically significant PVR rates we observed in this study.

\section{Comparison With Sutureless Aortic Valve Literature}

Sutureless AVR is undergoing clinical trials in the United States, but these devices are approved for use in Europe. There are already multiple studies reporting outcomes at short-term follow-up. PVR after sutureless AVR has a reported overall rate ranging from $2.3 \%$ to $8.1 \%$, with clinically significant moderate to severe PVR ranging from $0.3 \%$ to $0.9 \%$. In these early studies of sutureless AVR, reintervention for PVR at the time of initial operation is necessary in up to $4.3 \%$ of patients, and later reoperation is required in $0.9 \%$ to $4.3 \% .^{10,11,30}$ These short-term PVR rates compare favorably to those in our study, but the need for reintervention and reoperation for PVR after sutureless AVR appears to be higher. This will need to be followed as clinical trials and longer-term follow-up experience in cohort and ongoing US studies are reported.

\section{Study Limitations}

This is a retrospective review of prospectively collected data. It is a single-center study in an academic medical center and included experienced surgeons; thus, the current results may not be generalizable. However, this study was performed in a teaching program. There were approximately one quarter of patients without follow-up echocardiograms, reflecting the referral nature of the practice, which may introduce potential selection bias into the analysis. This could result in underreporting the incidence of PVR in the cohort. It is not unexpected to have a proportion of patients without follow-up echocardiography in this cohort, with a mean follow-up of less than 2.5 years, because the new American Society of Echocardiography and American Heart Association/American College of Cardiology guidelines do not recommend follow-up echocardiogram for surveillance until 5 to 10 years after surgery in the absence of a change 
in clinical status. ${ }^{14,31}$ On the contrary, the postdischarge echocardiograms may have a higher incidence of PVR, because patients with endocarditis and patients with a murmur, hemolysis, heart failure, or other suspicion may be more likely to undergo echocardiography. Clinical follow-up information was available in approximately $90 \%$ of patients with $100 \%$ undergoing predischarge echocardiography and $73 \%$ of patients with an echocardiogram in follow-up. For comparison, studies frequently cited for the historical incidence of PVR report $54 \%$ to $57 \%$ of patients with echocardiographic follow-up. ${ }^{7,21}$ Echocardiographic data were not evaluated by a centralized core echocardiography laboratory. This may have caused some variability in the identification of PVR and grading of its severity, but American Society of Echocardiography criteria were routinely used in the echocardiography laboratory. However, indeterminate regurgitation was included in the analysis and attributed to PVR, although some cases may have been valve related. In addition, some patients received mechanical valves $(2 \%$ aortic and $6 \%$ mitral) that could interfere with the detection of PVR due to shielding. This is a small proportion that would likely have a small effect on the overall PVR incidence.

\section{CONCLUSIONS}

In an academic medical center with a significant proportion of patients undergoing complex valve operations, the overall rate of PVR after AVR and MVR was low. Early intraoperative PVR requiring intervention was rare. Late clinically significant noninfectious PVR in AVR and MVR was rare, and there were no reoperations for noninfectious PVR. The benchmark for PVR by conventional surgical AVR or MVR is extremely high. As the use of TAVR expands to lower-risk groups, sutureless aortic valves gain Food and Drug Administration approval, and clinical trials on transcatheter MVR begin, this benchmark should be considered when counseling patients on valve replacement options.

\section{Conflict of Interest Statement}

Dr McCarthy: Edwards Lifesciences (consultant, royalties, intellectual property); Dr Thomas: Edwards Lifesciences (honoraria), Abbott (honoraria and consulting), GE (honoraria); Dr J. Davidson: Direct Flow Medical (personal fees), Edwards Lifesciences (grants); Dr Malaisrie: Edwards Lifesciences (consultant). All other authors have nothing disclose with regard to commercial support.

\section{References}

1. Genereux P, Head SJ, Hahn R, Daneault B, Kodali S, Williams MR, et al. Paravalvular leak after transcatheter aortic valve replacement: the new Achilles' heel? A comprehensive review of the literature. J Am Coll Cardiol. 2013;61: 1125-36.

2. Leon MB, Smith CR, Mack M, Miller DC, Moses JW, Svensson LG, et al. Transcatheter aortic-valve implantation for aortic stenosis in patients who cannot undergo surgery. N Engl J Med. 2010;363:1597-607.
3. Smith CR, Leon MB, Mack MJ, Miller DC, Moses JW, Svensson LG, et al. Transcatheter versus surgical aortic-valve replacement in high-risk patients. $N$ Engl J Med. 2011;364:2187-98.

4. Kodali SK, Williams MR, Smith CR, Svensson LG, Webb JG, Makkar RR, et al. Two-year outcomes after transcatheter or surgical aortic-valve replacement. $N$ Engl J Med. 2012;366:1686-95.

5. Adams DH, Popma JJ, Reardon MJ, Yakubov SJ, Coselli JS, Deeb GM, et al. Transcatheter aortic-valve replacement with a self-expanding prosthesis. $N$ Engl J Med. 2014;370:1790-8.

6. Hammermeister K, Sethi GK, Henderson WG, Grover FL, Oprian C, Rahimtoola SH. Outcomes 15 years after valve replacement with a mechanical versus a bioprosthetic valve: final report of the Veterans Affairs randomized trial J Am Coll Cardiol. 2000;36:1152-8.

7. O'Rourke DJ, Palac RT, Malenka DJ, Marrin CA, Arbuckle BE, Plehn JF. Outcome of mild periprosthetic regurgitation detected by intraoperative transesophageal echocardiography. J Am Coll Cardiol. 2001;38:163-6.

8. Sponga S, Perron J, Dagenais F, Mohammadi S, Baillot R, Doyle D, et al. Impact of residual regurgitation after aortic valve replacement. Eur J Cardiothorac Surg. 2012;42:486-92.

9. Lerakis S, Hayek SS, Douglas PS. Paravalvular aortic leak after transcatheter aortic valve replacement: current knowledge. Circulation. 2013;127:397-407.

10. Miceli A, Santarpino G, Pfeiffer S, Murzi M, Gilmanov D, Concistre G, et al. Minimally invasive aortic valve replacement with Perceval S sutureless valve: early outcomes and one-year survival from two European centers. J Thorac Cardiovasc Surg. 2014;148:2838-43.

11. Kocher AA, Laufer G, Haverich A, Shrestha M, Walther T, Misfeld M, et al. Oneyear outcomes of the Surgical Treatment of Aortic Stenosis With a Next Generation Surgical Aortic Valve (TRITON) trial: a prospective multicenter study of rapid-deployment aortic valve replacement with the EDWARDS INTUITY Valve System. J Thorac Cardiovasc Surg. 2013;145:110-6.

12. Davila-Roman VG, Waggoner AD, Kennard ED, Holubkov R, Jamieson WR Englberger L, et al. Prevalence and severity of paravalvular regurgitation in the Artificial Valve Endocarditis Reduction Trial (AVERT) echocardiography study J Am Coll Cardiol. 2004;44:1467-72.

13. Zoghbi WA, Enriquez-Sarano M, Foster E, Grayburn PA, Kraft CD, Levine RA, et al. Recommendations for evaluation of the severity of native valvular regurgitation with two-dimensional and Doppler echocardiography. J Am Soc Echocardiogr. 2003;16:777-802.

14. Zoghbi WA, Chambers JB, Dumesnil JG, Foster E, Gottdiener JS, Grayburn PA et al. Recommendations for evaluation of prosthetic valves with echocardiography and Doppler ultrasound: a report From the American Society of Echocardiography's Guidelines and Standards Committee and the Task Force on Prosthetic Valves, developed in conjunction with the American College of Cardiology Cardiovascular Imaging Committee, Cardiac Imaging Committee of the American Heart Association, the European Association of Echocardiography, a registered branch of the European Society of Cardiology, the Japanese Society of Echocardiography and the Canadian Society of Echocardiography, endorsed by the American College of Cardiology Foundation, American Heart Association, European Association of Echocardiography, a registered branch of the European Society of Cardiology, the Japanese Society of Echocardiography, and Canadian Society of Echocardiography. J Am Soc Echocardiogr. 2009;22: 975-1014. quiz 1082-14.

15. Detaint D, Lepage L, Himbert D, Brochet E, Messika-Zeitoun D, Iung B, et al Determinants of significant paravalvular regurgitation after transcatheter aortic valve: implantation impact of device and annulus discongruence. JACC Cardiovasc Interv. 2009;2:821-7.

16. Leon MB, Piazza N, Nikolsky E, Blackstone EH, Cutlip DE, Kappetein AP, et al Standardized endpoint definitions for Transcatheter Aortic Valve Implantation clinical trials: a consensus report from the Valve Academic Research Consortium. J Am Coll Cardiol. 2011;57:253-69.

17. Kappetein AP, Head SJ, Genereux P, Piazza N, van Mieghem NM, Blackstone EH, et al. Updated standardized endpoint definitions for transcatheter aortic valve implantation: the Valve Academic Research Consortium-2 consensus document. J Thorac Cardiovasc Surg. 2013;145:6-23.

18. Abdel-Wahab M, Zahn R, Horack M, Gerckens U, Schuler G, Sievert H, et al. Aortic regurgitation after transcatheter aortic valve implantation: incidence and early outcome. Results from the German transcatheter aortic valve interventions registry. Heart. 2011;97:899-906.

19. Taramasso M, Maisano F, Denti P, Guidotti A, Sticchi A, Pozzoli A, et al. Surgical treatment of paravalvular leak: long-term results in a single-center experience (up to 14 years). J Thorac Cardiovasc Surg. 2015;149:1270-5. 
20. Said SM. Paravalvular leak, the Achilles' heel of valve replacement: will transcatheter techniques be the answer? J Thorac Cardiovasc Surg. 2015;149:1276-7.

21. Ionescu A, Fraser AG, Butchart EG. Prevalence and clinical significance of incidental paraprosthetic valvar regurgitation: a prospective study using transoesophageal echocardiography. Heart. 2003;89:1316-21.

22. De Cicco G, Russo C, Moreo A, Beghi C, Fucci C, Gerometta P, et al. Mitral valve periprosthetic leakage: anatomical observations in 135 patients from a multicentre study. Eur J Cardiothorac Surg. 2006;30:887-91.

23. Abdel-Wahab M, Mehilli J, Frerker C, Neumann FJ, Kurz T, Tolg R, et al. Comparison of balloon-expandable vs self-expandable valves in patients undergoing transcatheter aortic valve replacement: the CHOICE randomized clinical trial. JAMA. 2014;311:1503-14.

24. Genereux P, Head SJ, Van Mieghem NM, Kodali S, Kirtane AJ, Xu K, et al. Clinical outcomes after transcatheter aortic valve replacement using valve academic research consortium definitions: a weighted meta-analysis of 3,519 patients from 16 studies. J Am Coll Cardiol. 2012;59:2317-26.

25. O'Sullivan KE, Gough A, Segurado R, Barry M, Sugrue D, Hurley J. Is valve choice a significant determinant of paravalular leak post-transcatheter aortic valve implantation? A systematic review and meta-analysis. Eur J Cardiothorac Surg. 2014;45:826-33.

26. Webb J, Gerosa G, Lefevre T, Leipsic J, Spence M, Thomas M, et al. Multicenter evaluation of a next-generation balloon-expandable transcatheter aortic valve. $J$ Am Coll Cardiol. 2014;64:2235-43.
27. Schofer J, Colombo A, Klugmann S, Fajadet J, DeMarco F, Tchetche D, et al Prospective multicenter evaluation of the direct flow medical transcatheter aortic valve. J Am Coll Cardiol. 2014;63:763-8.

28. Meredith IT, Worthley SG, Whitbourn RJ, Antonis P, Montarello JK, Newcomb AE, et al. Transfemoral aortic valve replacement with the reposition able Lotus Valve System in high surgical risk patients: the REPRISE I study. EuroIntervention. 2014;9:1264-70.

29. Schymik G, Lefevre T, Bartorelli AL, Rubino P, Treede H, Walther T, et al. European experience with the second-generation Edwards SAPIEN XT transcatheter heart valve in patients with severe aortic stenosis: 1-year outcomes from the SOURCE XT Registry. JACC Cardiovasc Interv. 2015;8:657-69.

30. Folliguet TA, Laborde F, Zannis K, Ghorayeb G, Haverich A, Shrestha M. Sutureless Perceval aortic valve replacement: results of two European centers. Ann Thorac Surg. 2012;93:1483-8.

31. Nishimura RA, Otto CM, Bonow RO, Carabello BA, Erwin JP III, Guyton RA, et al. 2014 AHA/ACC guideline for the management of patients with valvular heart disease: a report of the American College of Cardiology/American Heart Association Task Force on Practice Guidelines. J Thorac Cardiovasc Surg. 2014;148:e1-132.

Key Words: aortic valve replacement, mitral valve replacement, paravalvular regurgitation

\title{
EDITORIAL COMMENTARY
}

\section{Percutaneous aortic and mitral valve implantation. Is it ready to match the results of contemporary surgical valve replacement?}

\author{
Manuel J. Antunes, MD, PhD, DSc
}

From the Center of Cardiothoracic Surgery, University Hospital and Faculty of Medicine, Coimbra, Portugal. Disclosures: Author has nothing to disclose with regard to commercial support.

Received for publication July 2, 2015; accepted for publication July 6, 2015; available ahead of print Aug 13, 2015.

Address for reprints: Manuel J. Antunes, MD, PhD, DSc, Center of Cardiothoracic Surgery, University Hospital, 3000-075 Coimbra, Portugal (E-mail: antunes.cct.chuc@sapo.pt).

J Thorac Cardiovasc Surg 2015; 150:868-70

$0022-5223 / \$ 36.00$

Copyright (C) 2015 by The American Association for Thoracic Surgery

http://dx.doi.org/10.1016/j.jtcvs.2015.07.010

In this issue of the Journal, Duncan and colleagues ${ }^{1}$ deal with the problem of paravalvular regurgitation after conventional aortic and mitral valve replacement as a "benchmark for alternative approaches." The authors ${ }^{1}$ sought to determine the contemporary occurrence of paravalvular regurgitation after conventional surgical valve replacement. To this end, they analyzed retrospectively 1630 patients who underwent aortic and/or mitral valve replacement surgery at their institution over an 8.5-year period. Follow-up echocardiography was performed in $73 \%$ of patients and $a \geq 2+$ (moderate) paravalvular regurgitation occurred in $0.9 \%$ of aortic valve replacement and $2.2 \%$ of mitral valve replacement patients $(0.4 \%$ if infective endocarditis is excluded). They thus conclude that "the overall rate of paravalvular

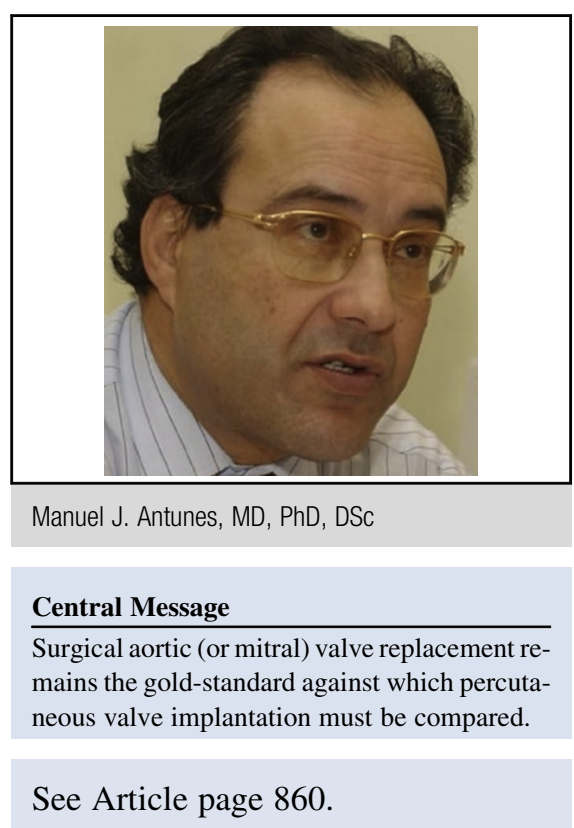

regurgitation is very low and late clinically significant structural (noninfectious) paravalvular regurgitation is rare", 
TABLE E1. Paravalvular regurgitation

\begin{tabular}{|c|c|c|c|c|}
\hline Variable & AVR only 1244 & MVR only 386 & AVR + MVR 144 & $P$ value \\
\hline Intraoperative PVR & $10(0.8 \%)$ & $8(2.1 \%)$ & $5(3.5 \%)$ & .009 \\
\hline Back on bypass for PVR repair & $5(0.4 \%)$ & $6(1.6 \%)$ & $4(2.8 \%)$ & .003 \\
\hline Discharge & 1214 & 362 & 137 & \\
\hline PVR 1+ & $3(0.2 \%)$ & $0(0 \%)$ & $1(0.7 \%)$ & .32 \\
\hline PVR $\geq 2+$ & $1(0.1 \%)$ & $1(0.3 \%)$ & $0(0 \%)$ & .58 \\
\hline Follow-up & 873 & 279 & 103 & \\
\hline PVR 1+ & $11(1.3 \%)$ & $2(0.7 \%)$ & $3(2.9 \%)$ & .24 \\
\hline $\mathrm{PVR} \geq 2+$ & $8(0.9 \%)$ & $6(2.2 \%)$ & $0(0 \%)$ & .12 \\
\hline Follow-up excluding SBE & 832 & 229 & 88 & \\
\hline PVR $1+$ & $9(1.1 \%)$ & $2(0.9 \%)$ & $2(2.3 \%)$ & .55 \\
\hline PVR $\geq 2+$ & $4(0.5 \%)$ & $1(0.4 \%)$ & $0(0 \%)$ & .81 \\
\hline Reoperation & 1089 & 327 & 120 & \\
\hline Reoperation for PVR in follow-up & $3(0.3 \%)$ & $4(1.2 \%)$ & $0(0 \%)$ & .06 \\
\hline
\end{tabular}

$A V R$, Aortic valve replacement; $M V R$, mitral valve replacement; $P V R$, paravalvular regurgitation; $S B E$, subacute bacterial endocarditis.

TABLE E2. Paravalvular regurgitation incidence by severity

\begin{tabular}{|c|c|c|c|c|c|c|}
\hline & None & Trace/trivial & $1+($ mild $)$ & $2+($ moderate $)$ & $3+($ moderate to severe $)$ & $4+($ severe $)$ \\
\hline \multicolumn{7}{|l|}{ AVR only } \\
\hline At discharge $(\mathrm{N}=1214)$ & $1195(98.4 \%)$ & $15(1.2 \%)$ & $3(0.2 \%)$ & $1(0.1 \%)$ & $0(0.0 \%)$ & $0(0.0 \%)$ \\
\hline In follow-up $(\mathrm{N}=873)$ & $845(96.8 \%)$ & $9(1.0 \%)$ & $11(1.3 \%)$ & $5(0.5 \%)$ & $1(0.1 \%)$ & $2(0.2 \%)$ \\
\hline In follow-up (no SBE) $(\mathrm{N}=832)$ & $810(97.4 \%)$ & $9(1.1 \%)$ & $9(1.1 \%)$ & $4(0.5 \%)$ & $0(0.0 \%)$ & $0(0.0 \%)$ \\
\hline In follow-up $(\mathrm{SBE})(\mathrm{N}=41)$ & $35(85.4 \%)$ & $0(0.0 \%)$ & $2(4.9 \%)$ & $1(2.4 \%)$ & $1(2.4 \%)$ & $2(4.9 \%)$ \\
\hline \multicolumn{7}{|l|}{ MVR only } \\
\hline At discharge $(\mathrm{N}=362)$ & $360(99.5 \%)$ & $1(0.3 \%)$ & $0(0.0 \%)$ & $0(0.0 \%)$ & $0(0.0 \%)$ & $1(0.3 \%)$ \\
\hline In follow-up $(\mathrm{N}=279)$ & $267(95.7 \%)$ & $4(1.4 \%)$ & $2(0.7 \%)$ & $0(0.0 \%)$ & $4(1.4 \%)$ & $2(0.7 \%)$ \\
\hline In follow-up (no SBE) $(\mathrm{N}=229)$ & $225(98.3 \%)$ & $1(0.4 \%)$ & $2(0.9 \%)$ & $0(0.0 \%)$ & $1(0.4 \%)$ & $0(0.0 \%)$ \\
\hline In follow-up $(\mathrm{SBE})(\mathrm{N}=50)$ & $42(84.0 \%)$ & $3(6.0 \%)$ & $0(0.0 \%)$ & $0(0.0 \%)$ & $3(6.0 \%)$ & $2(4.0 \%)$ \\
\hline \multicolumn{7}{|l|}{ AVR/MVR } \\
\hline At discharge $(\mathrm{N}=137)$ & $136(99.3 \%)$ & $0(0.0 \%)$ & $1(0.7 \%)$ & $0(0.0 \%)$ & $0(0.0 \%)$ & $0(0.0 \%)$ \\
\hline In follow-up $(N=103)$ & $97(94.2 \%)$ & $3(2.9 \%)$ & $3(2.9 \%)$ & $0(0.0 \%)$ & $0(0.0 \%)$ & $0(0.0 \%)$ \\
\hline In follow-up (no SBE) $(\mathrm{N}=88)$ & $84(95.5 \%)$ & $2(2.3 \%)$ & $2(2.3 \%)$ & $0(0.0 \%)$ & $0(0.0 \%)$ & $0(0.0 \%)$ \\
\hline In follow-up (SBE) $(\mathrm{N}=15)$ & $13(86.7 \%)$ & $1(6.7 \%)$ & $1(6.7 \%)$ & $0(0.0 \%)$ & $0(0.0 \%)$ & $0(0.0 \%)$ \\
\hline
\end{tabular}

$A V R$, Aortic valve replacement; $M V R$, mitral valve replacement; $S B E$, subacute bacterial endocarditis. 